\title{
Miniaturization of a Microstrip Patch Antenna with a Koch Fractal Contour Using a Social Spider Algorithm to Optimize Shorting Post Position and Inset Feeding
}

\author{
Eduardo A. M. Souza, ${ }^{1,2}$ Phelipe S. Oliveira, ${ }^{1}$ Adaildo G. D’Assunção $\mathbb{D}^{1}{ }^{1}$ \\ Laércio M. Mendonça, ${ }^{1}$ and Custódio Peixeiro ${ }^{3}$ \\ ${ }^{1}$ Department of Communication Engineering, Federal University of Rio Grande do Norte, Natal, RN, Caixa Postal 1655, \\ CEP: 59072-970, Brazil \\ ${ }^{2}$ Northeast Regional Centre, National Institute for Space Research, Natal, RN, CEP: 59076-740, Brazil \\ ${ }^{3}$ Instituto de Telecomunicações, Instituto Superior Técnico, University of Lisbon, Av. Rovisco Pais 1, 1049-001 Lisboa, Portugal
}

Correspondence should be addressed to Adaildo G. D’Assunção; adaildo@ymail.com

Received 17 August 2018; Revised 27 November 2018; Accepted 4 December 2018; Published 2 May 2019

Academic Editor: Sotirios K. Goudos

Copyright (C) 2019 Eduardo A. M. Souza et al. This is an open access article distributed under the Creative Commons Attribution License, which permits unrestricted use, distribution, and reproduction in any medium, provided the original work is properly cited.

\begin{abstract}
This paper presents a social spider optimization (SSO) design of a small-size microstrip antenna. Two antenna miniaturization techniques, based on the use of a Koch fractal contour and a shorting post (connecting the patch to the ground plane), are combined to enable a major size reduction. The antenna is inset fed by a microstrip line. The developed SSO algorithm is used to find out the best radius and position of the shorting post and the length of the inset feed, to achieve the desired resonant frequency with good impedance matching. Antenna prototypes have been fabricated and measured. The good agreement obtained between numerical simulation and experimental results has validated the design procedure. Compared with a conventional rectangular patch, the antenna resonance frequency is reduced from $2.45 \mathrm{GHz}$ to $730 \mathrm{MHz}$, which corresponds to a remarkable miniaturization of about $70 \%$. The proposed antenna is suitable for applications in the $700-800 \mathrm{MHz}$ frequency range, such as $4 \mathrm{G}$ mobile communication systems.
\end{abstract}

\section{Introduction}

Over the past few years, there has been an increasing demand for more reliable wireless mobile communication systems and a consistent trend to increase the required transmission capacity. Another aspect observed in the past few years is a growing need for devices, systems, and equipment for voice and data communications with smaller size and weight [1-6]. As a result, there has been a need to keep studying and proposing new techniques for the miniaturization of microstrip antennas [7-30].

Some of the required characteristics in antenna design for use in aircraft, spacecraft, and mobile wireless communication systems are reduced size and weight, low production cost, simplicity in the manufacturing process, flexible performance, ease of installation, mechanical robustness, printed circuit technology, and compatibility with monolithic microwave integrated circuits (MMIC). Microstrip antennas exhibit these advantageous features and, therefore, are suitable and widely used in communication system applications at the microwave and millimeter wave bands.

Several techniques have been used in the miniaturization of microstrip patch antennas [7], such as material loading [8, 9], shorting and folding [10-14], reshaping [15-20], modifying the ground plane $[21,22]$, using metamaterials [23-25], and using fractal contours [26-30].

Many bioinspired algorithms have been developed [31] and used to optimize different antenna geometries [32]. The most frequently used are neural networks $[33,34]$, genetic algorithms [34-36], and particle swarm optimization [37, 38]. 
This paper proposes the use of a Koch fractal geometry [16-20, 26-30] combined with a shorting post [10-13] to provide a very significant reduction of the resonant frequency enabling the miniaturization of a microstrip patch antenna. The approach is focused on the optimization of the shorting post (position and radius) and inset feeding line (width and length) using a social spider optimization (SSO) algorithm, based on the collective behavior of spiders $[39,40]$.

An antenna prototype has been fabricated and tested for comparison purposes. It is shown that, with the proposed technique, a small microstrip patch antenna can be designed to be used in the low frequency bands of the $4 \mathrm{G}$ mobile communication systems.

\section{Antenna Configuration}

This work proposes a single-layer microstrip antenna composed of a conducting patch with a Koch fractal contour and a single shorting post, to get reduction in size and weight for a specific resonance frequency.

The Koch fractal is a self-similar fractal with iterative construction defined by the iteration number $k$, also called the fractal level, and the iteration factor $d$. It is classified as a deterministic geometry composed of several copies of itself. As shown in Figure 1(a), the initiator is a rectangular microstrip patch antenna with width $W$ and length $L$. The initiator is also known as a Koch fractal patch of level $k=0$. The Koch (loop) fractal generation process is started by replacing the upper, lower, left, and right sides of the initiator by those defined by the fractal generator, as shown in Figure 1(b), being called the Koch fractal patch of level $k=1$. Fractal iteration factors $d_{L}=1 / 3$ (in length) and $d_{W}=1 / 3$ (in width) are used, resulting in $W_{1}=W / 3$ and $L_{1}=L / 3$.

In order to get further resonance frequency reduction, the upper, lower, left, and right sides of the Koch fractal patch of level $k=1$ are replaced by those defined by the fractal generator, as shown in Figure 1(c), being called the Koch fractal patch of level $k=2$, where $W_{2}=W_{1} / 3$ and $L_{2}=L_{1} / 3$.

A shorting post connecting the conducting patch to the ground plane is used (as shown in Figure 2) to get an additional reduction of the antenna resonance frequency, enabling further miniaturization. The shorting post radius is $R_{s}$, and its position is $\left(x_{s}, y_{s}\right)$, as also shown in Figure 2.

The proposed antenna is inset fed by a microstrip line with inset width $X_{0}$ and length $Y_{0}$, for an impedance matching purpose. An SMA connector is connected (soldered) to the microstrip line and a $50 \Omega$ coaxial cable is connected to the SMA connector. Both are used to excite the antenna.

The ground plane dimensions of the antenna are $W_{\mathrm{GP}}$ and $L_{\mathrm{GP}}$. The dielectric substrate is FR4, with relative permittivity $\varepsilon_{r}=4.4$, loss tangent $\tan \delta=0.02$, and thickness $h=1.5 \mathrm{~mm}$.

Particularly, the position and diameter of the shorting post (SP) directly affect the resonance frequency reduction. Similarly, the antenna reflection coefficient is directly affected by the width and length of the inset in the microstrip feed line.

To determine the best shorting post radius, $R_{s}$, and position, $\left(x_{s}, y_{s}\right)$, and the inset width, $X_{0}$, and length, $Y_{0}$, a social spider optimization (SSO) algorithm has been developed.

\section{Social Spider Algorithm Optimization}

Recently, a new optimization algorithm has been proposed for a bandstop Vicsek fractal frequency selective surface and a planar monopole antenna design [40]. This optimization technique, introduced in [39] and called social spider optimization (SSO), has been inspired in the social behavior of male and female spiders, to improve the avoidance of premature convergence in the optimization process.

In this work, the SSO technique is used in the design of a compact microstrip patch antenna with a fractal contour and a shorting post (Figure 2). Each spider represents a set of values for the shorting post radius $R_{s}$ and position $\left(x_{s}, y_{s}\right)$ and inset of the microstrip feed line width $X_{0}$ and length $Y_{0}$. In this case, to keep the symmetry of the antenna structure and radiation pattern, $x_{s}=0$ is imposed. These antenna dimensions are randomly defined in their variation intervals and directly used in the Ansoft HFSS software tool to obtain the antenna resonant frequency, $f_{r}$, and reflection coefficient, $S_{11}$, values, to be used in the SSO algorithm. The proposed SSO algorithm does not require storage of large amounts of data or the use of interpolation techniques enabling the development of efficient and accurate antenna analysis. A detailed description of the proposed SSO algorithm is included in [40].

The first step in the SSO analysis is the generation of the initial population. In the second step, a fitness function is used to compute the spider proximity of the optimal solution. Depending on the distance, the spider receives a weight that indicates the quality of the solution. This weight is computed using the values of the antenna resonant frequency, $f_{r}$, and reflection coefficient, $S_{11}$. Each spider receives a calculated value according to its weight, and this value takes into account a portion of $70 \%$ of $f_{r}$ and $30 \%$ of $S_{11}$. In the third step, all the spiders are checked to determine if the desired values for $f_{r}$ and $S_{11}$ were achieved. In the affirmative case, the algorithm execution is stopped; otherwise, the positions of male and female spiders are changed, and the algorithm execution continues $[39,40]$.

In the fourth step, the way the spiders' positions are changed depends on their sexes. Basically, female spiders are attracted or repulsed by other spiders, determining and distinguishing their solution quality. Male spiders are classified as dominant and nondominant, according to their weight or quality of the solution [39].

The fifth and last step in the SSO technique is the mating operation, followed by an evaluation of all the spiders and the beginning of a new cycle. The execution of the algorithm continues until a spider reaches a particular position in the web, i.e., finds adequate values for $X_{0}, Y_{0}, y_{s}$, and $R_{s}$ to achieve the desired values for the antenna resonant 


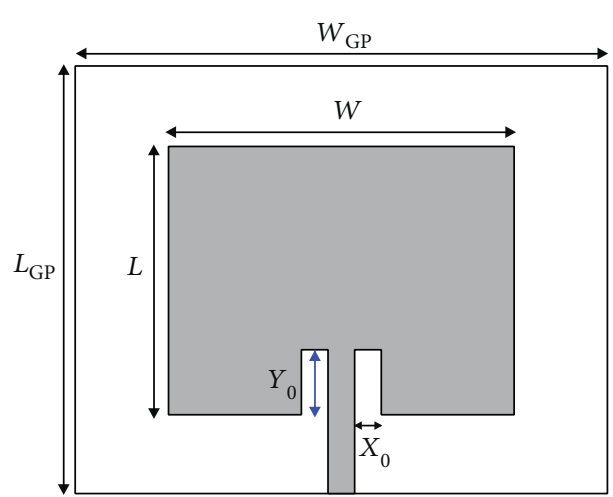

(a)

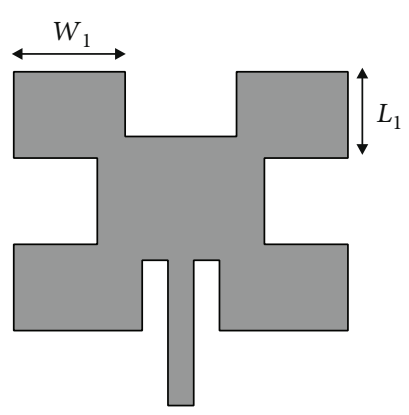

(b)

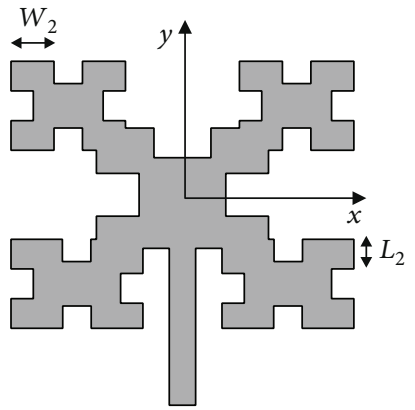

(c)

FIGURE 1: Microstrip patch antenna with (a) Koch fractal contour of level $k=0$ (initiator), (b) Koch fractal contour of level $k=1$, and (c) Koch fractal contour of level $k=2$.

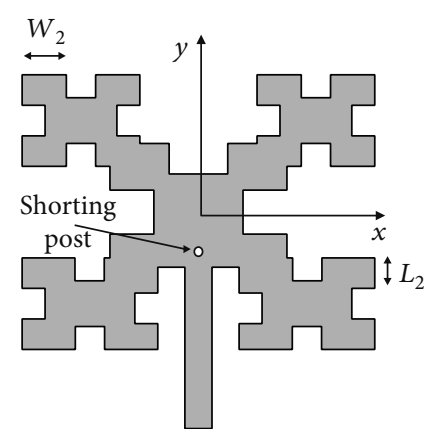

FIgURE 2: Microstrip patch antenna with Koch fractal contour of level $k=2$ and the shorting post.

frequency, $f_{r}$ and input reflection coefficient, $S_{11}$. The specific fitness function used is

$$
f_{\text {fitness }}=\left\{\begin{array}{l}
{\left[\frac{\left(f_{r}-f_{\text {goal }}\right)}{f_{\text {goal }}}\right], \quad \text { if } f_{r} \neq f_{\text {goal }},} \\
\frac{10}{S_{11}^{2}}, \quad \text { if } f_{r}=f_{\text {goal }},
\end{array}\right.
$$

where $f_{\text {goal }}$ is the required resonance frequency and $S_{11}$ is the input reflection coefficient (in $\mathrm{dB}$ ) at the frequency $f_{\text {goal }}$. In this case, the goals are $f_{\text {goal }}=730 \mathrm{MHz}$ and $S_{11} \leq-10 \mathrm{~dB}$.

In this specific geometry, only 4 parameters have been considered for optimization $\left(X_{0}, Y_{0}, y_{s}\right.$, and $\left.R_{s}\right)$; however, in general terms, the more complex the problem is (more optimization variables), the more advantageous would the SSO algorithm be.

\section{Results and Discussion}

Figure 3 shows simulation results for the $S_{11}$ frequency behavior of rectangular patch microstrip antennas with Koch fractal geometries of levels $k=1$ and $k=2$, without the shorting post, as shown in Figures 1(b) and 1(c). Simulation results for the $S_{11}$ frequency behavior of the initial rectangular patch (corresponding to the fractal level $k=0$ ) are also included for reference. The dimensions of the initiator, shown in Figure $1(\mathrm{a})$, are $L=29.09 \mathrm{~mm}, W=37.34 \mathrm{~mm}$, $L_{\mathrm{GP}}=47.47 \mathrm{~mm}, W_{\mathrm{GP}}=57.34 \mathrm{~mm}, W_{\mathrm{TL}}=2.87 \mathrm{~mm}, X_{0}=$ $2.87 \mathrm{~mm}$, and $Y_{0}=7.84 \mathrm{~mm}$. These initial values have been chosen to provide a good impedance matching to a 50 $\mathrm{Ohm}$ microstrip line at $2.45 \mathrm{GHz}$. These dimensions are the same for the fractal geometries of levels $k=1$ and $k=2$, corresponding to Figures 1(b) and 1(c).

The use of Koch fractal geometries decreases the resonance frequency enabling a significant size reduction of the antenna. The obtained resonance frequencies, for the microstrip antennas shown in Figures $1(\mathrm{a})-1(\mathrm{c})$, are $2.45 \mathrm{GHz}, 1.70 \mathrm{GHz}$, and $1.37 \mathrm{GHz}$, for Koch fractal levels $k=0$ (initiator), $k=1$, and $k=2$, respectively.

The proposed Koch fractal patch antenna with the shorting post shown in Figure 2 is investigated for further miniaturization. The analysis has been carried out through a combination of the developed social spider optimization (SSO) algorithm and Ansoft HFSS software, to simultaneously optimize the inset microstrip feed line width $X_{0}$ and length $Y_{0}$ (Figure $1(\mathrm{a})$ ) and the antenna shorting post radius $R_{s}$ and position $y_{s} . W_{\mathrm{TL}}=2.87 \mathrm{~mm}$ provides the required 50 Ohm characteristic impedance for the microstrip feed line.

The results shown in Figure 4 correspond to the antenna geometry shown in Figure 2 with the shorting post (radius $R_{s}$ and position $y_{s}$ ) and inset of the feeding transmission line dimensions (width $X_{0}$ and length $Y_{0}$ ) calculated by the developed social spider optimization (SSO) algorithm. The obtained antenna dimensions are $R_{s}=0.04 \mathrm{~mm}, y_{s}=-4.835$ $\mathrm{mm}, X_{0}=3.805 \mathrm{~mm}$, and $Y_{0}=8.71 \mathrm{~mm}$. The other antenna structural parameters are the same as the ones used to get the results shown in Figure 3. The obtained resonance frequencies, for the fractal patch antenna without and with the shorting post, are $1.37 \mathrm{GHz}$ and $730 \mathrm{MHz}$, respectively.

When compared with the initial common rectangular patch, the optimized patch of fractal level 2 with the shorting post presents a reduction of $70.2 \%$ in resonance frequency, $41.7 \%$ in impedance bandwidth, and $81.2 \%$ in radiation efficiency. Gain follows the radiation efficiency reduction rate. 


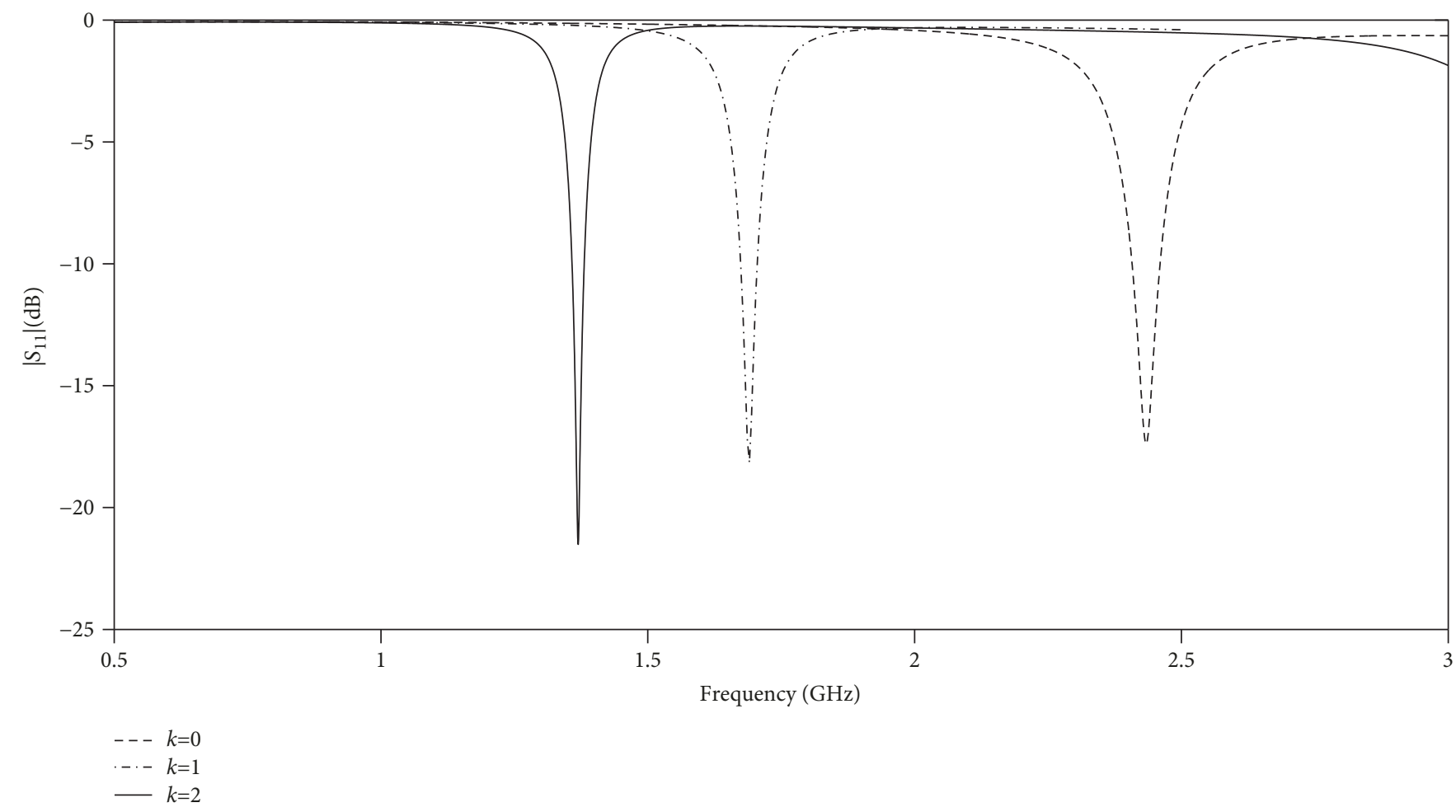

FIGURE 3: Simulation results for the reflection coefficient of the Koch fractal antennas of levels $k=0$ (initiator), $k=1$, and $k=2$, without the shorting post.

The optimized antenna with the Koch fractal level $k=2$ contour and the shorting post has been fabricated using conventional printing circuit technology. Photographs of the antenna prototype and anechoic chamber measurement setup are shown in Figure 5.

The numerical simulations have shown that the optimal solution with the integration of the shorting post led to a significant reduction of the antenna resonant frequency provided by the sole use of the Koch fractal geometry of level $k=2$.

As a consequence of the miniaturization process, the bandwidth and efficiency of the patch have been decreased. This is a well-known and well-documented option [7, 41]. Table 1 contains first resonance frequency, impedance bandwidth (defined for a magnitude of $S_{11}$ equal to $-10 \mathrm{~dB}$ ), and radiation efficiency results.

Apart from bandwidth, the characteristics of the miniaturized antenna are adequate for application in $4 \mathrm{G}$ mobile communication devices. Bandwidth can be enhanced using several techniques [42], such as substrate topology [43] and/or stacked patches [44].

Figure 6 shows a comparison between simulation and experimental results for the reflection coefficient. A good agreement is observed. As already pointed out, the simulation results have been obtained with the Ansoft HFSS software tool. The antenna simulation and measured resonance frequency results are $730 \mathrm{MHz}$ and $744 \mathrm{MHz}$, respectively, which corresponds to just $1.9 \%$ difference.

Figure 7 shows simulation and experimental results for the $E$-plane ( $y z$ plane) and $H$-plane ( $x z$ plane) radiation pattern cuts of the proposed Koch fractal antenna of level $k=2$ with a shorting post, at $744 \mathrm{MHz}$. Measurements have been made in an anechoic chamber environment. A reasonable good agreement is obtained between simulation and experimental results. The shadowing effect of the positioner where the antenna is mounted can be observed in the experimental results for the angular range $180 \pm 30$ degrees.

Moreover, significant discrepancy can be noticed in the $E$-plane in the angular range 210-270 degrees and almost everywhere in the $H$-plane. These discrepancies are mostly caused by the poor performance of the anechoic chamber, which is specified to be used above $2 \mathrm{GHz}$. The reflectivity of the absorbing material (for oblique incidence) used in the anechoic chamber is only about $-16 \mathrm{~dB}$ at $744 \mathrm{MHz}$, in contrast with the $-30 \mathrm{~dB}$ obtained at $2 \mathrm{GHz}$. Due to the small ground plane size [45], the spurious radiation of the coaxial feed cable could also contribute to the above-mentioned discrepancy. However, the tests made with ferrite chokes [46] have shown that the influence of the coaxial feed currents is not meaningful.

\section{Sensitivity Analysis}

To illustrate the complexity of the developed optimization process, the antenna resonant frequency, $f_{r}$, and reflection coefficient, $S_{11}$, dependences on the independent variables $R_{s}, y_{s}, X_{0}$, and $Y_{0}$ are shown in Figures 8-11, for four particular cases around the SSO obtained values. In each case, three of the antenna dimensions are fixed, and the fourth 


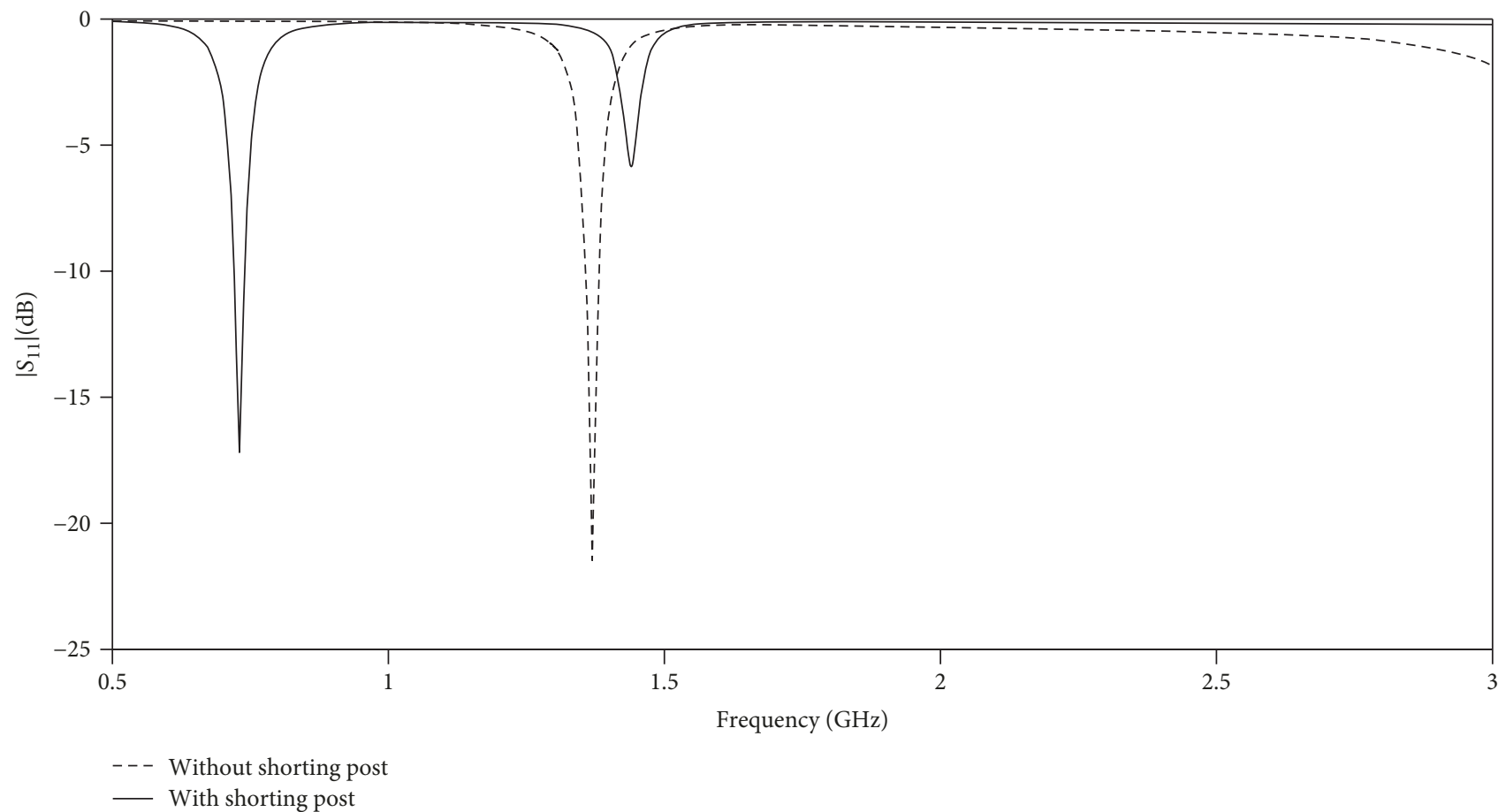

FIGURE 4: Simulation results for the reflection coefficient of Koch fractal antenna of level $k=2$, without and with the shorting post.

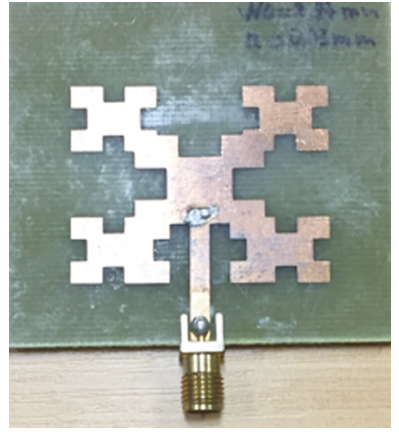

(a)

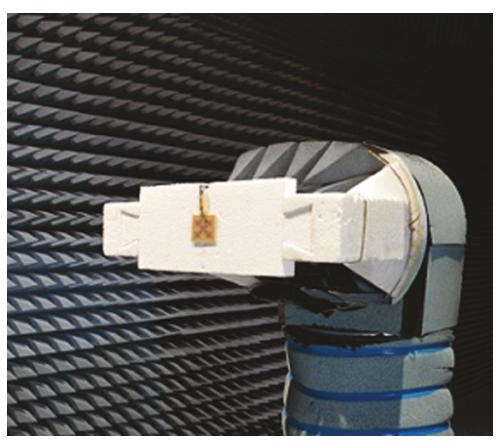

(b)

Figure 5: Photographs of the proposed antenna alone (a) and in an anechoic chamber measurement setup (b).

TABLE 1: Comparison of resonance frequency, bandwidth, and radiation efficiency simulation results.

\begin{tabular}{lccc}
\hline & Resonance frequency (GHz) & Bandwidth (\%) & Radiation efficiency (\%) \\
\hline Patch without the shorting post (fractal level 0) & 2.45 & 2.35 & 58.6 \\
Patch without the shorting post (fractal level 1) & 1.70 & 1.78 & 27.4 \\
Patch without the shorting post (fractal level 2) & 1.37 & 1.77 & 14.8 \\
Patch with the shorting post (fractal level 2) & 0.73 & 1.37 & 11.0 \\
\hline
\end{tabular}

one is varied. The following antenna structural parameters are used in all the four cases: $W=29.09 \mathrm{~mm}, L=37.34 \mathrm{~mm}$, $W_{\mathrm{GP}}=57.34 \mathrm{~mm}, L_{\mathrm{GP}}=47.47 \mathrm{~mm}, W_{\mathrm{TL}}=2.87 \mathrm{~mm}$, and $x_{s}=0 \mathrm{~mm}$.

The resonant frequency dependences of the shorting post location $y_{s}$ and radius $R_{s}$ are illustrated in Figures 8 and 9 , respectively.
Figure 8 shows a strong dependence of the resonant frequency on the shorting post location, $y_{s}$, indicating an increasing antenna miniaturization ability for increasing values of the distance $y_{s}$. Similarly, Figure 9 shows a strong dependence of the resonant frequency on the shorting post radius, $R_{s}$. However, in this case, the antenna miniaturization ability increases for decreasing values of 


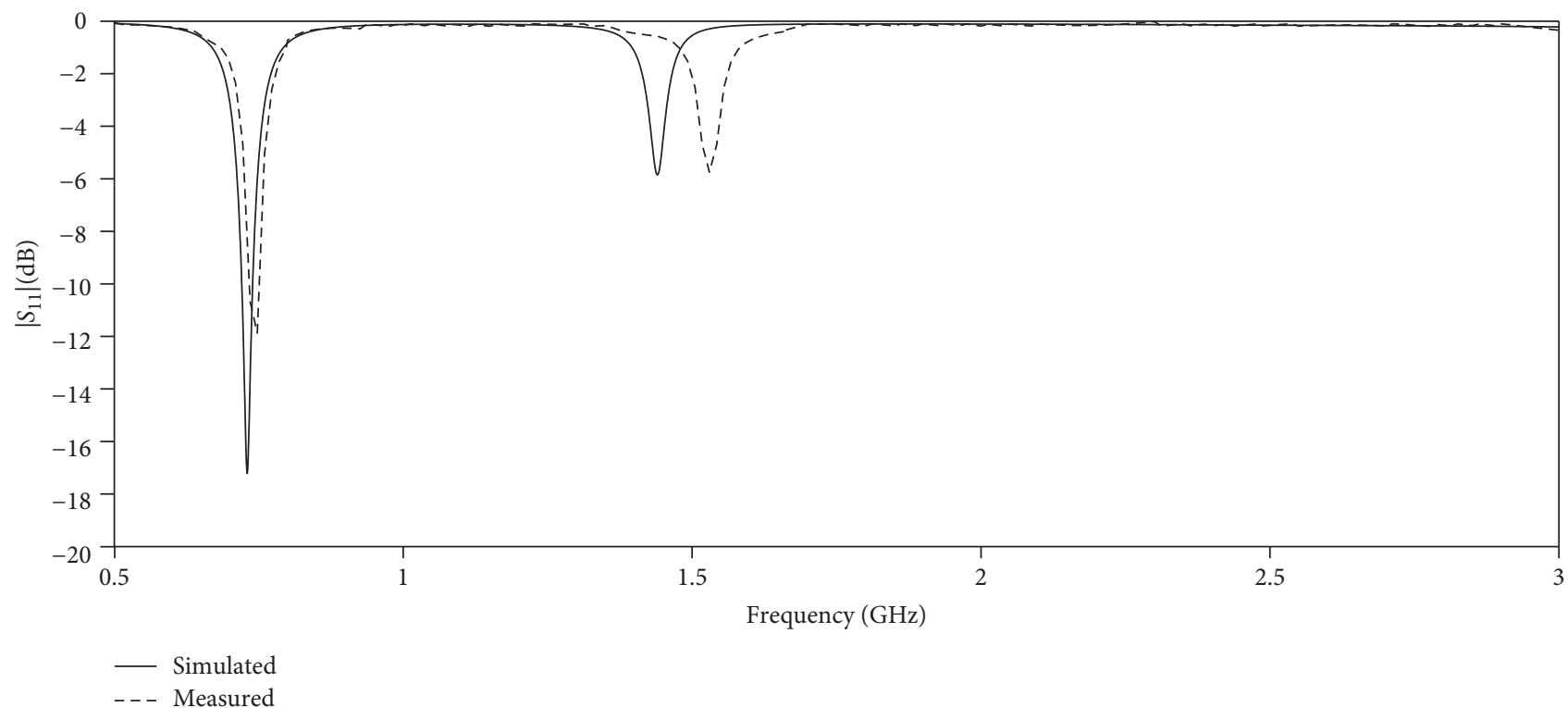

FIGURE 6: Reflection coefficient simulation and experimental results of the SSO optimized Koch fractal antenna.

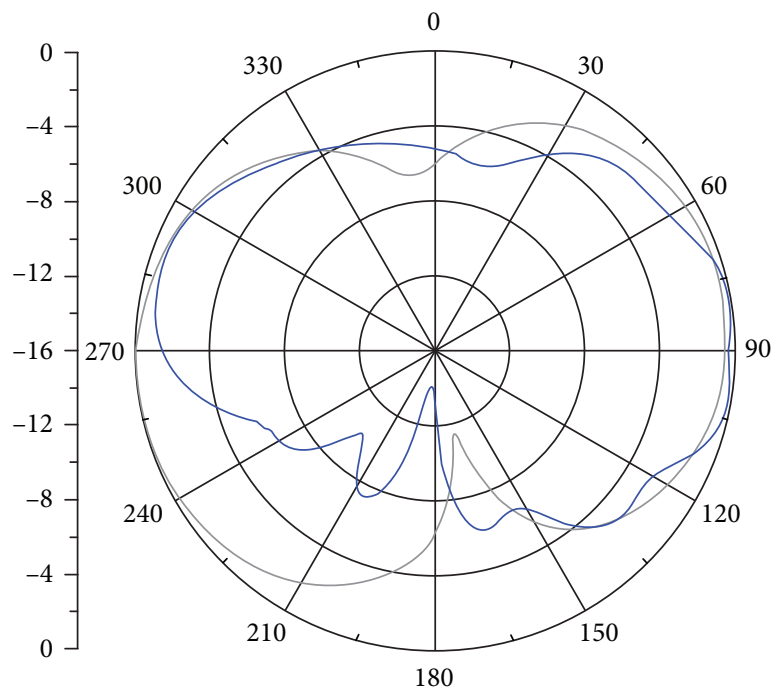

E-plane simulated

- E-plane measured

(a)

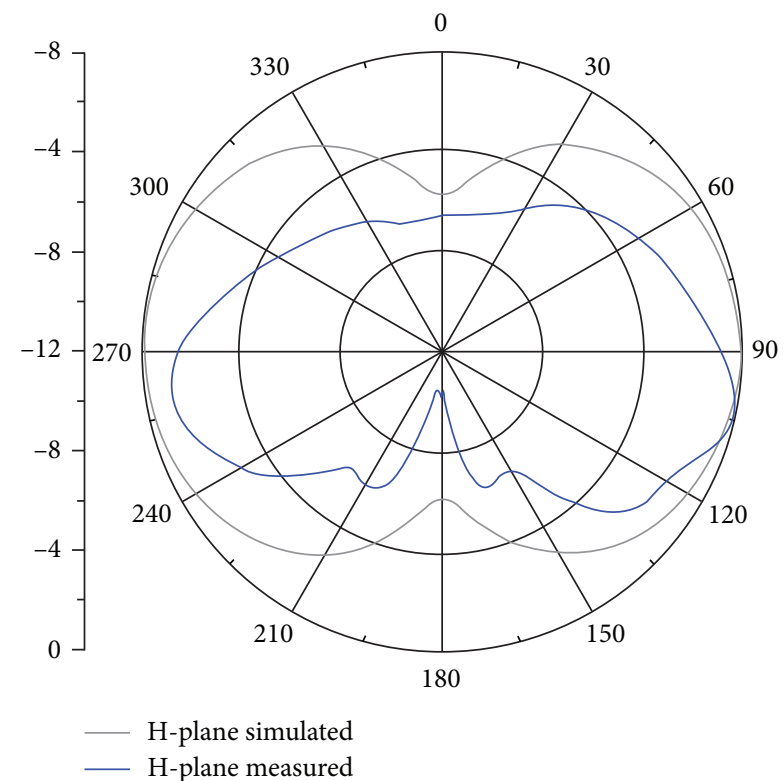

(b)

FIGURE 7: Radiation pattern simulation and experimental results of the SSO optimized Koch fractal antenna at $744 \mathrm{MHz}$.

$R_{s} . R_{s}=0.04 \mathrm{~mm}$ has been chosen as it was the smaller value that could be implemented.

Figures 10 and 11 show, respectively, the dependence of the reflection coefficient $S_{11}$ at $730 \mathrm{MHz}$, on the inset feed length $Y_{0}$ and width $X_{0}$, indicating the impedance matching ability of the miniaturized antenna with the shorting post.

It is important to point out that the optimal value of a parameter depends on the stop criteria used in the SSO algorithm. As it can be seen in Figures 10 and 11, there are values of $X_{0}$ and $Y_{0}$ that lead to lower values of $\left|S_{11}\right|$ than the ones obtained with the SSO process.

\section{Comparison with a PSO Algorithm}

This section provides a convergence rate comparison with another global optimization method, the particle swarm optimization (PSO) [37], for the specific problem under optimization. As shown in Figure 12, the SSO algorithm is significantly better, as it reaches convergence at iteration 


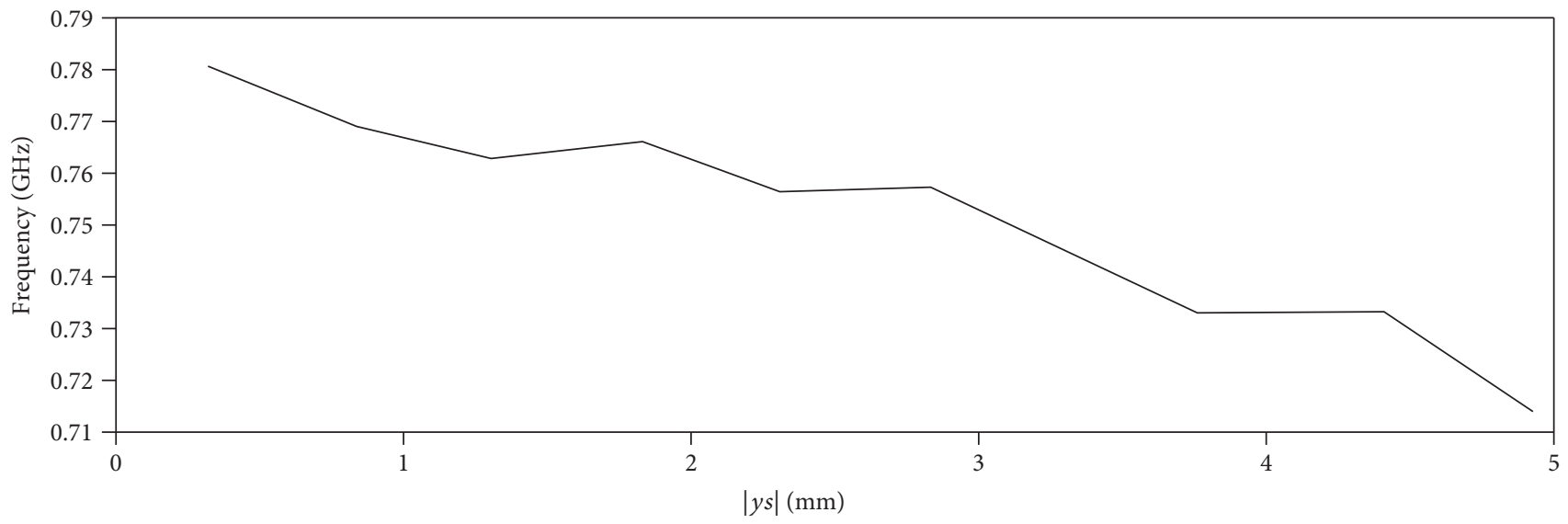

FIGURE 8: Simulation results for the resonant frequency dependence of the shorting post location $y_{s}$ for the Koch fractal antenna of level $k=2$.

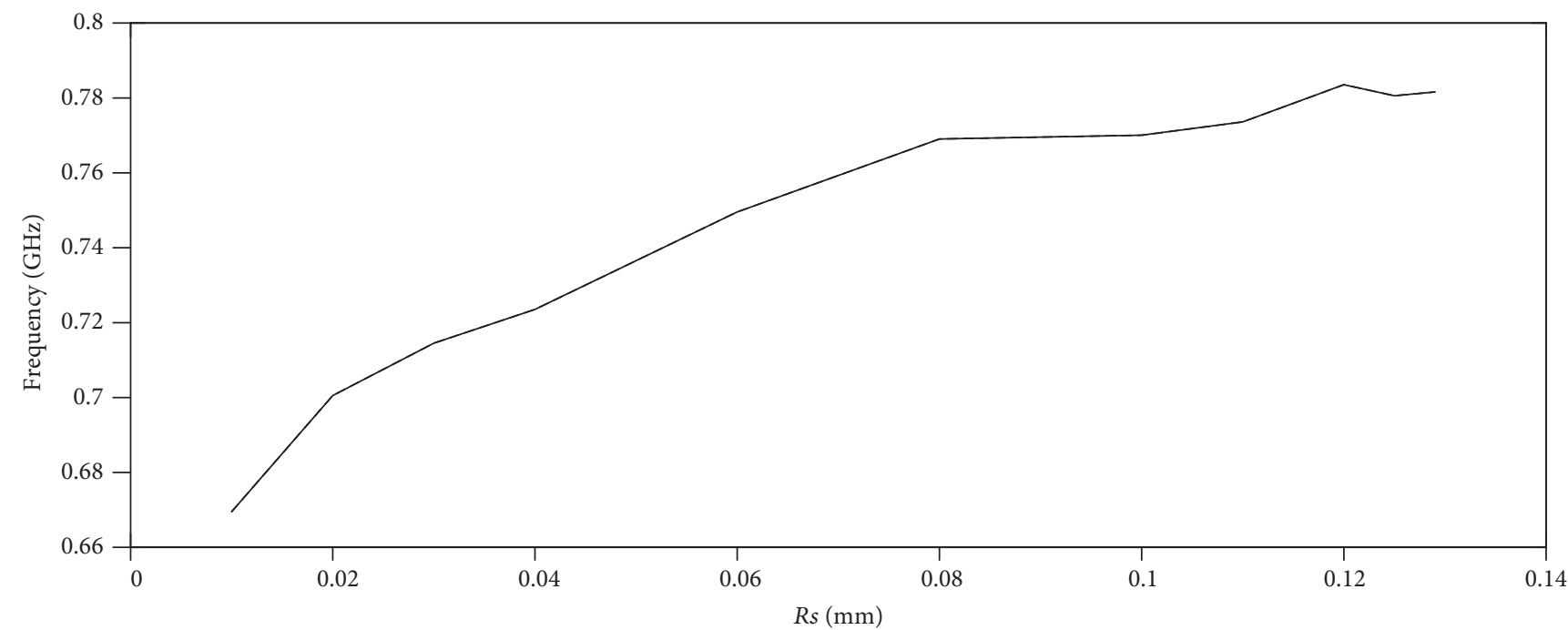

FIGURE 9: Simulation results for the resonant frequency dependence of the shorting post radius $R_{s}$ for the Koch fractal antenna of level $k=2$.

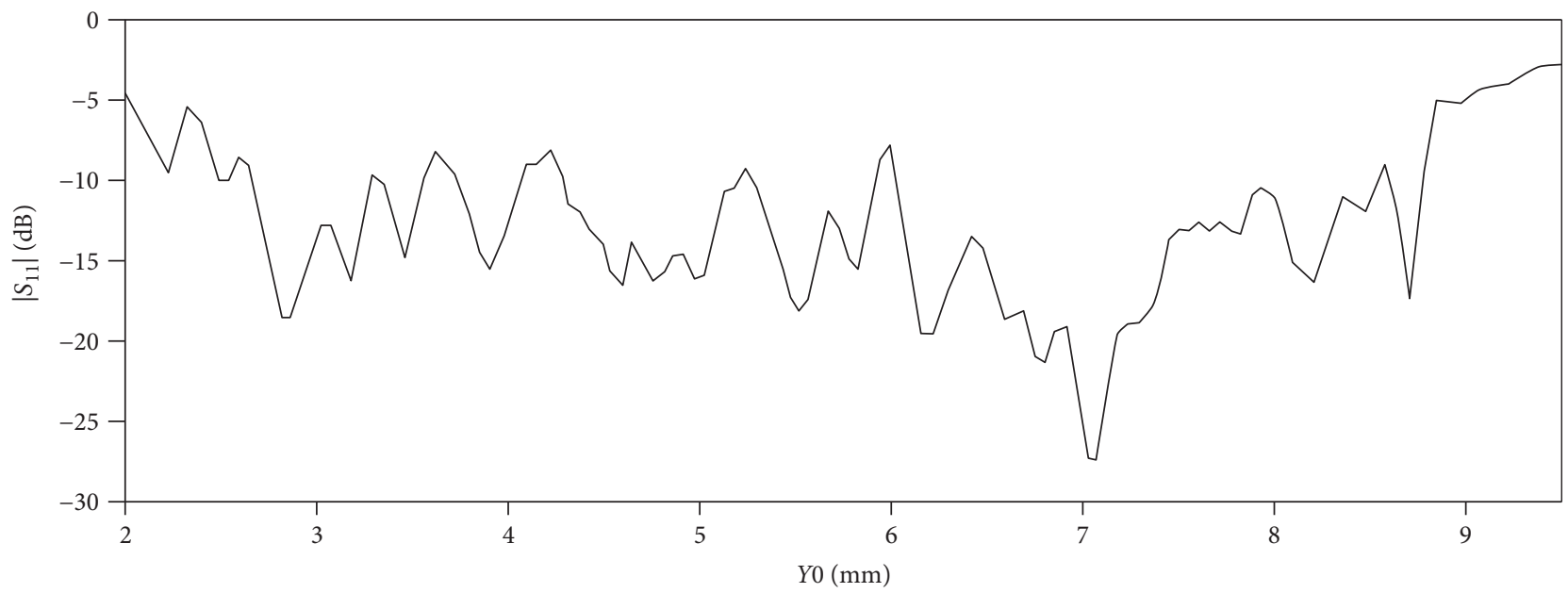

FIGURE 10: Simulation results for the reflection coefficient dependence of the inset feed length $Y_{0}$, for the Koch fractal antenna of level $k=2$ with the shorting post. 


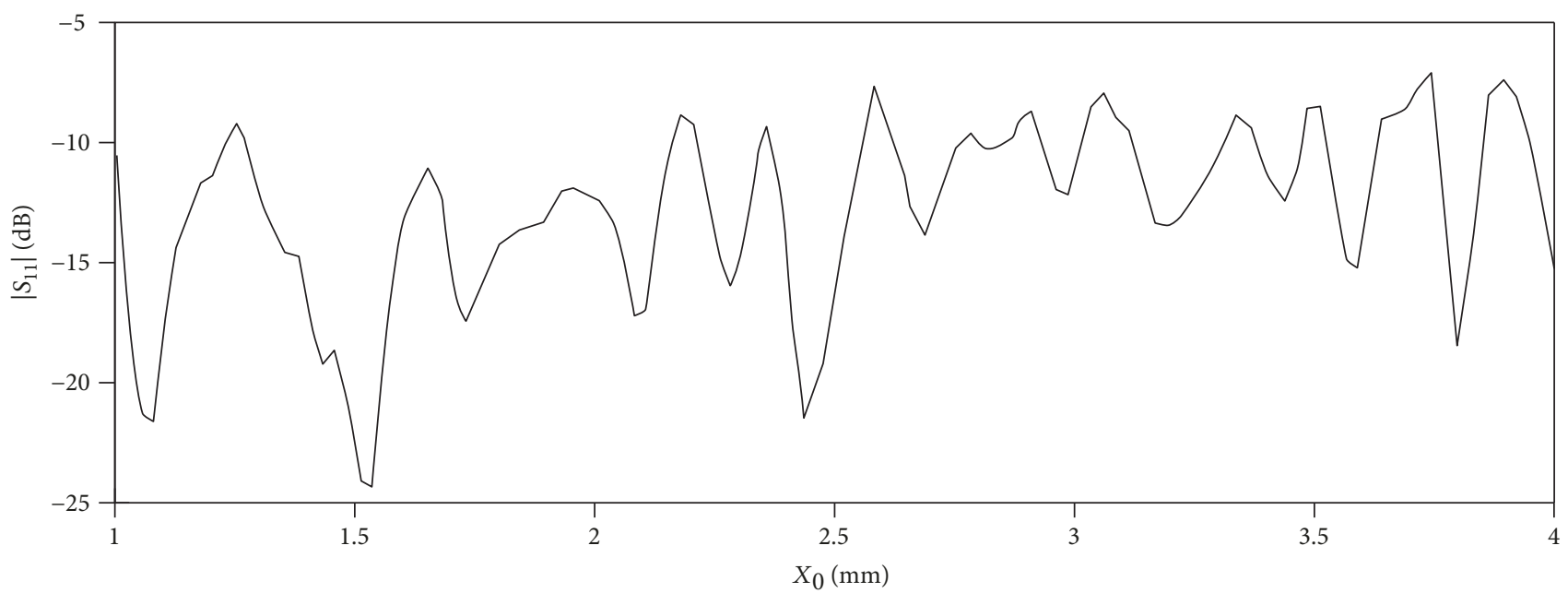

Figure 11: Simulation results for the reflection coefficient dependence of the inset feed width $X_{0}$, for the Koch fractal antenna of level $k=2$ with the shorting post.

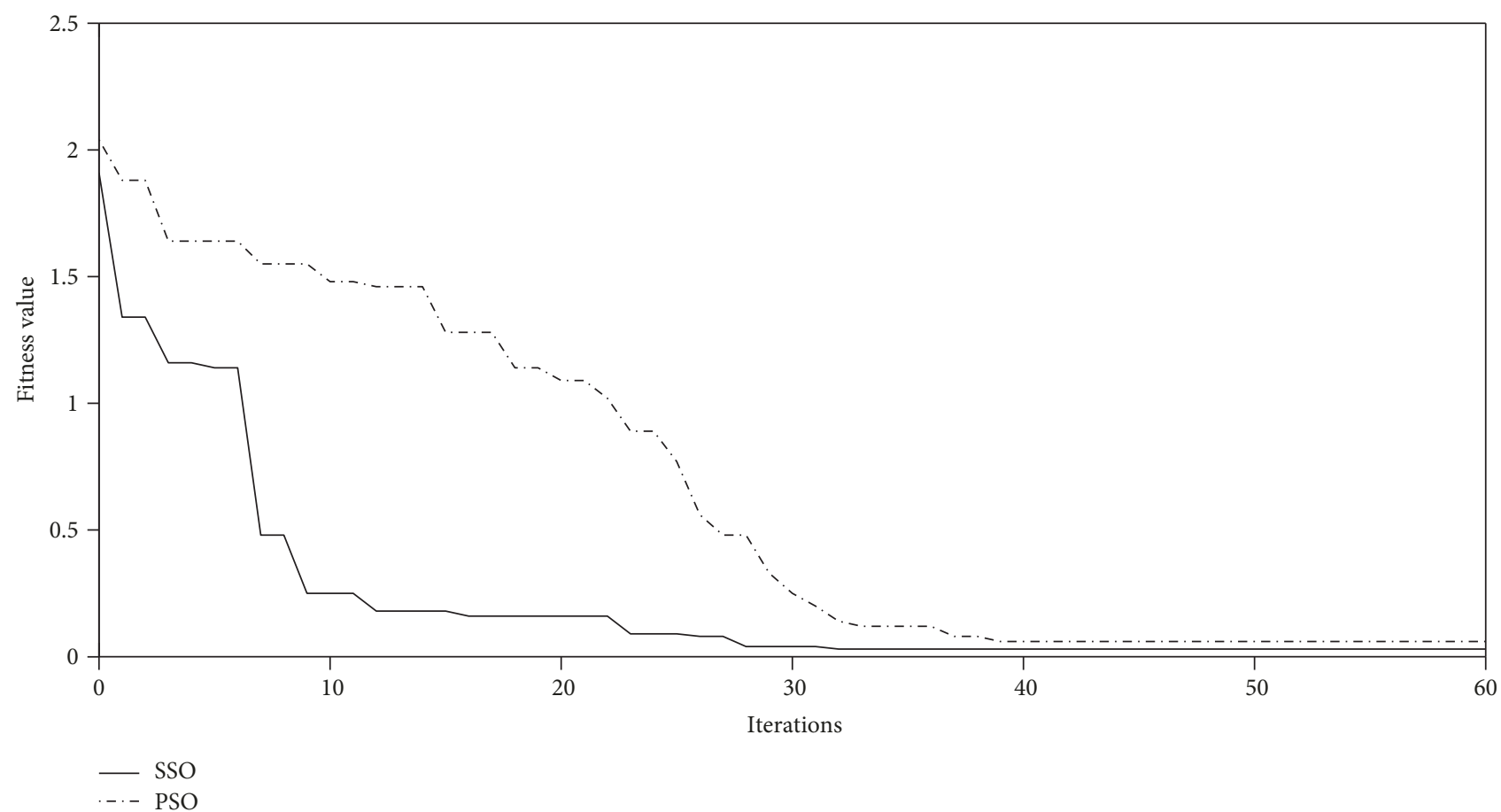

FIGURE 12: Comparison of the convergence of SSO and PSO algorithms.

32 whereas for the PSO 39, iterations are needed. For a fair comparison, the same population size (12) has been used in both methods.

The computational effort of the two methods is quite similar. The calculation time in a workstation with an Intel Xeon E5506 $2.13 \mathrm{GHz}$ processor and $24 \mathrm{~GB}$ of RAM is about 40 minutes for each generation of 12 individuals. Only about $2 \%$ of this computation time is used directly by the optimization algorithm; the remaining $98 \%$ is used by HFSS.

\section{Conclusion}

A compact microstrip antenna has been optimized using a social spider optimization (SSO) algorithm. The microstrip antenna is composed of a conducting patch with Koch fractal shape and a shorting post. An optimization technique based on an SSO algorithm is used to obtain the position and radius of the shorting post and the inset feed length and width. The use of the fractal geometry in conjunction with the shorting post resulted in a substantial size reduction when compared 
with other miniaturization techniques. The provided antenna miniaturization is about $70 \%$ in comparison with the size of the initial rectangular patch geometry. An antenna prototype has been fabricated and tested to proof the proposed concept. The good agreement obtained between numerical simulation and experimental results has validated the design procedure. The miniaturized antenna is suitable for operation in the $700-800 \mathrm{MHz}$ frequency range, being a good candidate for applications in the low frequency bands of $4 \mathrm{G}$ mobile communication systems.

\section{Data Availability}

Data is available on request sent to the corresponding author to the e-mail address adaildo@ct.ufrn.br.

\section{Conflicts of Interest}

The authors declare that there is no conflict of interests regarding the publication of this paper.

\section{Acknowledgments}

The authors thank the support received from $\mathrm{CNPq}$, under contract 573939/2008-0 (INCT-CSF), Universidade Federal do Rio Grande do Norte (UFRN), National Institute for Space Research (INPE), and Fundação para a Ciência e a Tecnologia under the grant UID/EEA/50008/2019.

\section{References}

[1] G. Kumar and K. P. Ray, Broadband Microstrip Antennas, Artech House, 2003.

[2] V. Rabinovich and N. Alexandrov, Antenna Arrays and Automotive Applications, Springer, 2013.

[3] P. Callaghan and J. C. Batchelor, "Dual-band pin-patch antenna for Wi-Fi applications," IEEE Antennas and Wireless Propagation Letters, vol. 7, pp. 757-760, 2008.

[4] M. Naser-Moghadasi, R. A. Sadeghzadeh, T. Sedghi, T. Aribi, and B. S. Virdee, "UWB CPW-fed fractal patch antenna with band-notched function employing folded T-shaped element," IEEE Antennas and Wireless Propagation Letters, vol. 12, pp. 504-507, 2013.

[5] I. Venneri, A. Borgia, L. Boccia, G. Amendola, and G. Di Massa, "Millimeter waves patch antenna design and realization on BCB polymer substrates," in 2008 IEEE Antennas and Propagation Society International Symposium, pp. 1-4, San Diego, CA, USA, 2008.

[6] A. Sharma, V. K. Dwivedi, and G. Singh, "THz rectangular microstrip patch antenna on multilayered substrate for advance wireless communication systems," in Progress in Electromagnetics Research Symposium, pp. 627-631, Beijing, China, 2009.

[7] M. U. Khan, M. S. Sharawi, and R. Mittra, "Microstrip patch antenna miniaturisation techniques: a review," IET Microwaves, Antennas \& Propagation, vol. 9, no. 9, pp. 913-922, 2015.

[8] D. Schaubert and K. Yngvesson, "Experimental study of a microstrip array on high permittivity substrate," IEEE Transactions on Antennas and Propagation, vol. 34, no. 1, pp. 92-97, 1986.
[9] A. Hoorfar and A. Perrotta, "An experimental study of microstrip antennas on very high permittivity ceramic substrates and very small ground planes," IEEE Transactions on Antennas and Propagation, vol. 49, no. 5, pp. 838-840, 2001.

[10] R. Porath, "Theory of miniaturized shorting-post microstrip antennas," IEEE Transactions on Antennas and Propagation, vol. 48, no. 1, pp. 41-47, 2000.

[11] S. W. Wong, T. G. Huang, C. X. Mao, Z. N. Chen, and Q. X. $\mathrm{Chu}$, "Planar filtering ultra-wideband (UWB) antenna with shorting pins," IEEE Transactions on Antennas and Propagation, vol. 61, no. 2, pp. 948-953, 2013.

[12] A. K. Bhattacharyya, "Bandwidth limits of multilayer array of patches excited with single and dual probes and with a shorting post," IEEE Transactions on Antennas and Propagation, vol. 59, no. 3, pp. 818-825, 2011.

[13] J. Wu, X. Ren, Z. Wang, and Y. Yin, "Broadband circularly polarized antenna with L-shaped strip feeding and shortingpin loading," IEEE Antennas and Wireless Propagation Letters, vol. 13, pp. 1733-1736, 2014.

[14] R. Li, G. de Jean, M. M. Tentzeris, and J. Laskar, "Development and analysis of a folded shorted-patch antenna with reduced size," IEEE Transactions on Antennas and Propagation, vol. 52, no. 2, pp. 555-562, 2004.

[15] N. Herscovici, M. F. Osorio, and C. Peixeiro, "Miniaturization of rectangular microstrip patches using genetic algorithms," IEEE Antennas and Wireless Propagation Letters, vol. 1, pp. 94-97, 2002.

[16] J. P. Gianvittorio and Y. Rahmat-Samii, "Fractal antennas: a novel antenna miniaturization technique, and applications," IEEE Antennas and Propagation Magazine, vol. 44, no. 1, pp. 20-36, 2002.

[17] M. Taghadosi, L. Albasha, N. Qaddoumi, and M. Ali, "Miniaturised printed elliptical nested fractal multiband antenna for energy harvesting applications," IET Microwaves, Antennas \& Propagation, vol. 9, no. 10, pp. 1045-1053, 2015.

[18] A. Amini, H. Oraizi, and M. A. Chaychi zadeh, "Miniaturized UWB log-periodic square fractal antenna," IEEE Antennas and Wireless Propagation Letters, vol. 14, pp. 13221325, 2015.

[19] A. Azari, "A new super wideband fractal microstrip antenna," IEEE Transactions on Antennas and Propagation, vol. 59, no. 5, pp. 1724-1727, 2011.

[20] A. R. Maza, B. Cook, G. Jabbour, and A. Shamim, "Paperbased inkjet-printed ultra-wideband fractal antennas," IET Microwaves, Antennas \& Propagation, vol. 6, no. 12, pp. 1366-1373, 2012.

[21] H. V. Prabhakar, U. K. Kummuri, R. M. Yadahalli, and V. Munnappa, "Effect of various meandering slots in rectangular microstrip antenna ground plane for compact broadband operation," Electronics Letters, vol. 43, no. 16, p. 848, 2007.

[22] D. Wang, H. Wong, and C. H. Chan, "Small patch antennas incorporated with a substrate integrated irregular ground," IEEE Transactions on Antennas and Propagation, vol. 60, no. 7, pp. 3096-3103, 2012.

[23] K. Z. Rajab, R. Mittra, and M. T. Lanagan, "Size reduction of microstrip patch antennas with left-handed transmission line loading," IET Microwaves, Antennas \& Propagation, vol. 1, no. 1, pp. 39-44, 2007.

[24] A. Alu, F. Bilotti, N. Engheta, and L. Vegni, "Subwavelength, compact, resonant patch antennas loaded with metamaterials," 
IEEE Transactions on Antennas and Propagation, vol. 55, no. 1, pp. 13-25, 2007.

[25] R. O. Ouedraogo, E. J. Rothwell, A. R. Diaz, K. Fuchi, and A. Temme, "Miniaturization of patch antennas using a metamaterial-inspired technique," IEEE Transactions on Antennas and Propagation, vol. 60, no. 5, pp. 2175-2182, 2012.

[26] D. H. Wqrner and S. Ganguly, "An overview of fractal antenna engineering research," IEEE Antennas and Propagation Magazine, vol. 45, no. 1, pp. 38-57, 2003.

[27] S. Costanzo, F. Venneri, G. Di Massa, A. Borgia, A. Costanzo, and A. Raffo, "Fractal reflectarray antennas: state of art and new opportunities," International Journal of Antennas and Propagation, vol. 2016, Article ID 7165143, 17 pages, 2016.

[28] H. Rmili, D. Oueslati, I. B. Trad, J. M. Floch, A. Dobaie, and R. Mittra, "Investigation of a random-fractal antenna based on a natural tree-leaf geometry," International Journal of Antennas and Propagation, vol. 2017, Article ID 2084835, 7 pages, 2017.

[29] D. R. Minervino, A. G. D'Assunção, and C. Peixeiro, "Mandelbrot fractal microstrip antennas," Microwave and Optical Technology Letters, vol. 58, no. 1, pp. 83-86, 2016.

[30] V. P. Silva Neto and A. G. D’Assunção, "Iterative full-wave analysis of Mandelbrot-inspired fractal patch antenna on textile substrate for UWB applications," International Journal of Antennas and Propagation, vol. 2017, Article ID 4686315, 6 pages, 2017.

[31] A. K. Kar, "Bio inspired computing - a review of algorithms and scope of applications," Expert Systems with Applications, vol. 59, pp. 20-32, 2016.

[32] S. H. Yeung, W. S. Chan, K. T. Ng, and K. F. Man, "Computational optimization algorithms for antennas and RF/microwave circuit designs: an overview," IEEE Transactions on Industrial Informatics, vol. 8, no. 2, pp. 216-227, 2012.

[33] A. Freni, M. Mussetta, and P. Pirinoli, "Neural network characterization of reflectarray antennas," International Journal of Antennas and Propagation, vol. 2012, Article ID 541354, 10 pages, 2012.

[34] W. C. de Araújo, H. W. C. Lins, A. G. D'Assunção Jr, J. L. G. Medeiros, and A. G. D'Assunção, "A bioinspired hybrid optimization algorithm for designing broadband frequency selective surfaces," Microwave and Optical Technology Letters, vol. 56, no. 2, pp. 329-333, 2014.

[35] R. L. Haupt and D. H. Werner, Genetic Algorithms in Electromagnetics, John Wiley \& Sons, Inc., 2007.

[36] E. J. B. Rodrigues, A. G. D'Assunção, H. W. C. Lins, and C. Peixeiro, "Genetic algorithm optimization of a CPW fed UWB circular ring monopole with modified ground plane," Microwave and Optical Technology Letters, vol. 58, no. 6, pp. 1319-1323, 2016.

[37] J. Robinson and Y. Rahmat-Samii, "Particle swarm optimization in electromagnetics," IEEE Transactions on Antennas and Propagation, vol. 52, no. 2, pp. 397-407, 2004.

[38] E. J. B. Rodrigues, H. W. C. Lins, and A. G. D'Assunção, "Fast and accurate synthesis of electronically reconfigurable annular ring monopole antennas using particle swarm optimisation and artificial bee colony algorithms," IET Microwaves, Antennas \& Propagation, vol. 10, no. 4, pp. 362-369, 2016.

[39] E. Cuevas, M. Cienfuegos, D. Zaldívar, and M. Pérez-Cisneros, "A swarm optimization algorithm inspired in the behavior of the social-spider," Expert Systems with Applications, vol. 40, no. 16, pp. 6374-6384, 2013.
[40] P. S. Oliveira, A. G. D'Assunção, E. A. M. Souza, and C. Peixeiro, "A fast and accurate technique for FSS and antenna designs based on the social spider optimization algorithm," Microwave and Optical Technology Letters, vol. 58, no. 8, pp. 1912-1917, 2016.

[41] S. R. Best, "Electrically small resonant planar antennas: optimizing the quality factor and bandwidth," IEEE Antennas and Propagation Magazine, vol. 57, no. 3, pp. 38-47, 2015.

[42] R. B. Waterhouse, S. D. Targonski, and D. M. Kokotoff, "Design and performance of small printed antennas," IEEE Transactions on Antennas and Propagation, vol. 46, no. 11, pp. 1629-1633, 1998.

[43] G. Kiziltas, D. Psychoudakis, J. L. Volakis, and N. Kikuchi, "Topology design optimization of dielectric substrates for bandwidth improvement of a patch antenna," IEEE Transactions on Antennas and Propagation, vol. 51, no. 10, pp. 2732-2743, 2003.

[44] E. Nishiyama, M. Aikawa, and S. Egashira, "Stacked microstrip antenna for wideband and high gain," IEE Proceedings - Microwaves, Antennas and Propagation, vol. 151, no. 2, pp. 143-148, 2004.

[45] M. S. Ellis, Z. Zhao, J. Wu, Q. H. Liu, and Z. Nie, "Small planar monopole ultra-wideband antenna with reduced ground plane effect," IET Microwaves, Antennas \& Propagation, vol. 9, no. 10, pp. 1028-1034, 2015.

[46] C. Icheln, J. Ollikainen, and P. Vainikainen, "Reducing the influence of feed cables on small antenna measurements," Electronics Letters, vol. 35, no. 15, pp. 1212-1214, 1999. 


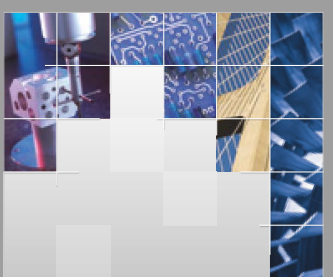

\section{Enfincering}
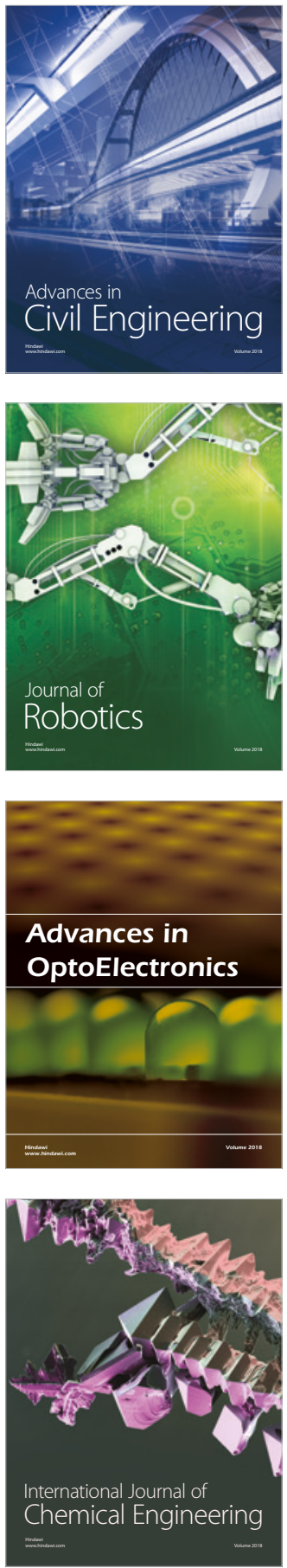

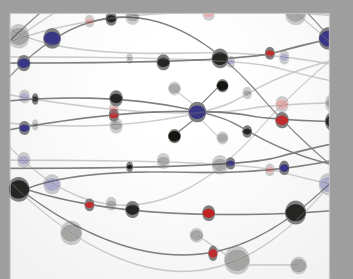

\section{Rotating \\ Machinery}

The Scientific World Journal

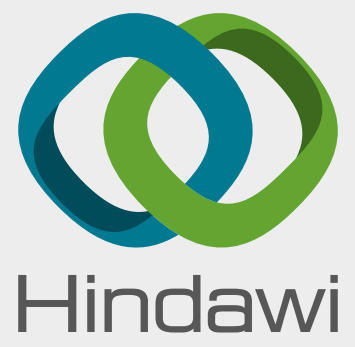

Submit your manuscripts at

www.hindawi.com
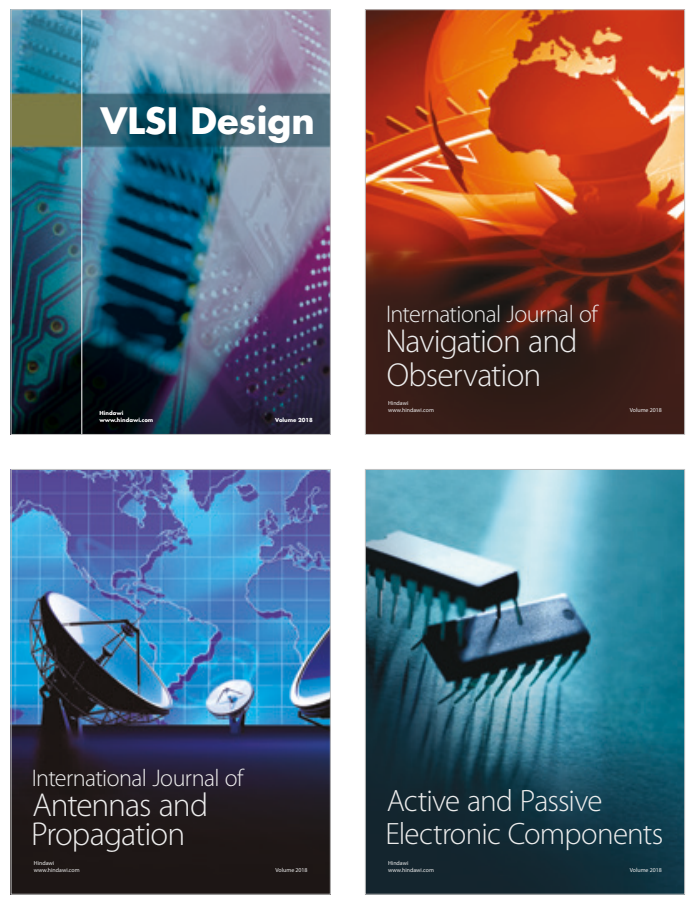
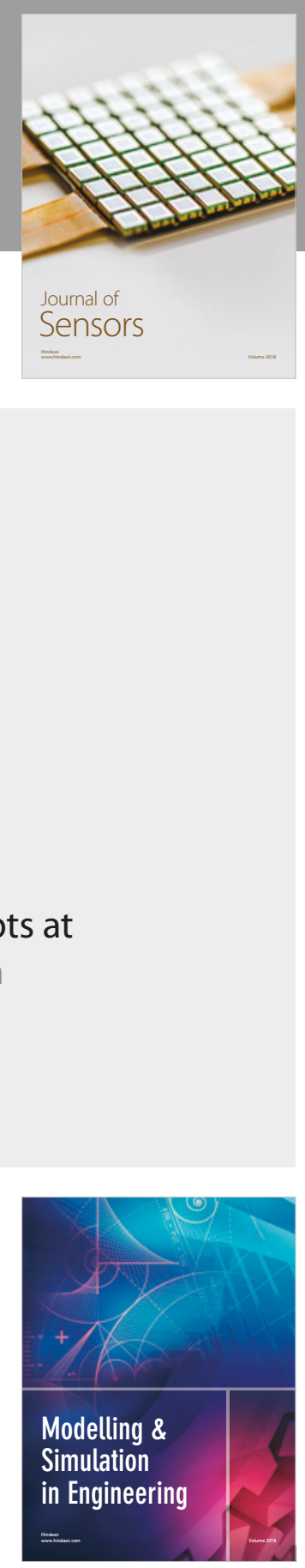

\section{Advances \\ Multimedia}
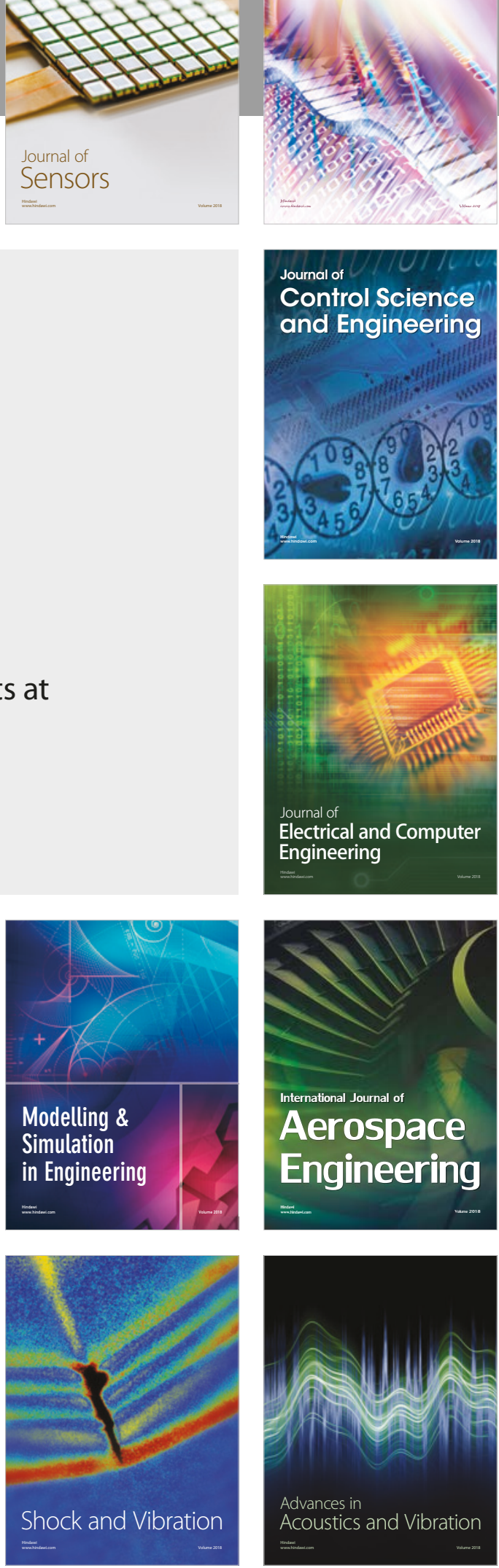